\title{
Obtenção de concentrado protéico de folhas e parte aérea da mandioca (Manihot esculenta Crantz)
}

\section{Protein concentrate obtainment from leaves and aerial part cassava (Manihot esculenta Crantz)}

\author{
Janaina Lima da Silva'; Simone Damasceno Gomes; \\ Silvia Renata Machado Coelho ${ }^{3}$; Janete Evarini ${ }^{4}$; Priscila Ferri ${ }^{1}$; \\ Marney Pascoli Cereda ${ }^{5}$; Shaiane Dal' Maso Lucas ${ }^{6 *}$
}

\begin{abstract}
Resumo
As partes aéreas da mandioca, representadas pelas folhas, hastes e caules, constituem-se como resíduos agroindustriais por serem desperdiçadas na colheita das raízes. Esse material possui valor protéico, vitaminas e mineiras, propiciando sua utilização como suplemento alimentar nas indústrias alimentícias. Alternativas neste sentido surgem para extrair a proteína das folhas e eliminar os agentes tóxicos e antinutricionais naturalmente presentes em sua composição. Neste contexto, o objetivo desta pesquisa foi avaliar rendimento, composição mineral e propriedades funcionais de concentrados protéicos, obtidos de folhas e parte aérea de mandioca. Na extração das proteínas, foram testados os métodos de (1) Precipitação Isoelétrica, (2) Fermentação Natural por 5 dias, (3) Fermentação por 48 horas e (4) Fermentação por 48 horas, seguida de ajuste de $\mathrm{pH}$. Foi utilizado o delineamento fatorial 2x4, sendo os fatores o tipo de material (folhas e parte aérea) e o método de extração de proteína (quatro métodos), com três repetições. O Método 1 proporcionou os maiores rendimentos de concentrado protéico e extração de proteína das folhas de mandioca, porém, não foi verificada diferença significativa entre os métodos de extração para a parte aérea da mandioca. Os teores de Fe, Mn e Zn aumentaram nos concentrados protéicos da parte aérea da mandioca, com destaque para o Método 3. As capacidades de absorção de água e de óleo dos concentrados protéicos foram elevadas para os quatro métodos avaliados, indicando boa aplicação em produtos alimentícios.
\end{abstract}

Palavras-chave: Proteína, métodos de extração, propriedades funcionais

\footnotetext{
Abstract

The aerial parts of cassava, constituted by leaves, stalk sand stems, are considered as agro-industrial waste, so, they are thrown away during roots crop. This material has content of protein, vitamin and mineral; therefore, it can be used as a dietary supplement for food industries. Thus, alternatives have come to extract protein from leaves and remove toxic agent sand anti-nutrients that make part of their composition. In this context, this study aimed at evaluating yield, mineral composition and functional

${ }^{1}$ Engenehira(s) Química(s), Mestre em Engenharia Agrícola, Universidade Estadual do Oeste do Paraná, UNIOESTE, Cascavel, PR. E-mail:cg_msms@alvaro.com.br; priscila.ferri@bol.com.br

${ }^{2}$ Prof $^{a}$ Associada, CCET/PGEAGRI/UNIOESTE, Cascavel, PR. E-mail: simone.gomes@unioeste.br

${ }^{3}$ Prof $^{\text {a }}$ Adjunta, CCET/PGEAGRI/UNIOESTE, Cascavel, PR. E-mail: silvia.coelho@unioeste.br

${ }^{4}$ Bióloga, Laboratório de Saneamento, Dept ${ }^{\circ}$ de Engenharia Agrícola, UNIOESTE, Cascavel, PR. E-mail: janyevarini@yahoo. com.br

${ }^{5}$ Prof $^{a}$ Titular, Universidade Católica Dom Bosco, Campo Grande, MS. E-mail: cereda@ucdb.br

${ }^{6}$ Tecnóloga em Gerenciamento Ambiental, Doutoranda em Engenharia Agrícola, UNIOESTE, Cascavel, PR. E-mail: shaiane. lucas@yahoo.com.br

* Autor para correspondência
} 
properties of protein concentrates from leaves and aerial part of cassava. During the extraction of proteins, the following tested methods were:(1) isoelectric precipitation; (2) natural fermentation for five days; (3) fermentation for 48 hours and (4) fermentation for 48 hours, followed by pH adjustment. A $2 \times 4$ factorial design was used, the studied factors were the products (leaves and shoots) and the method of protein extraction (four methods), with three replications. From the results, it was observed that Method 1 provided the highest yields of protein concentrate and protein extraction for cassava leaves, however, there was no significant difference among the extraction methods for the aerial part of cassava. The values of $\mathrm{Fe}, \mathrm{Mn}$ and $\mathrm{Zn}$ increased in protein concentrates obtained both in leaves and the aerial part of cassava, especially for Method 3. The capacities of absorbing water and oil from protein concentrates were considered high for the four studied methods, thus, indicating a good application in food products.

Key words: Protein, methods of extraction, functional properties

\section{Introdução}

No Brasil são produzidos cerca de 26 milhões de toneladas anuais de mandioca (IBGE, 2012), colocando esta cultura entre as principais do país. A mandioca (Manihot esculenta Crantz) é cultivada nas mais diversas regiões brasileiras e sua produção tem sido dirigida tanto para consumo direto, como para indústria de transformação (DIAS; LEONEL, 2006).

Paralelamente à alta produção desta cultura, surgem grandes quantidades de resíduos agroindustriais, dentre eles a parte aérea da planta na colheita das raízes que podem, segundo Sagrilo et al. (2008), atingir cerca de duas toneladas por hectare em matéria seca.A parte aérea da planta, normalmente desperdiçada, apresenta alta produtividade, contendo folhas de elevado teor protéico, entre 15 e $40 \%$ em massa seca, vitaminas e minerais a baixo custo, dependendo da variedade, idade da planta e manejo da cultura (MODESTI et al., 2007; PEQUENO et al., 2007; SILVA et al., 2009; ALETOR, 2010).

Devido ao bom aporte de proteínas, minerais, aminoácidos e vitaminas, as folhas de mandioca podem ser utilizadas como suplemento alimentar, tanto para o homem como para animais (FASUYI; ALETOR, 2005; MELO et al., 2007; BOHNENBERGER et al., 2010). Porém, seu consumo direto fica limitado pela presença de agentes tóxicos e antinutricionais, como polifenóis (taninos), inibidores da tripsina, saponina, hemaglutinina e cianeto, necessitando passar por processos que reduzam sua concentração, além de reduzir a parte fibrosa, que não é digerida por humanos e animais monogástricos (MELO et al., 2007; MODESTI et al., 2007; WOBETO et al., 2007; TEO et al., 2010).

Dentro deste contexto, muitos trabalhos surgem com alternativas para extrair as proteínas e melhorar o aproveitamento das folhas, obtendose concentrados protéicos de folhas de mandioca (CPFM). Esses CPFM tem se mostrado adequado como ingrediente funcional na aplicação de diversos alimentos, apresentando baixo teor de fibras e teores de proteína, na base seca, na faixa de 30\%(LEONEL, 2001; CEREDA; VILPOUX, 2003; MODESTI et al., 2007; TEO et al., 2010). Segundo Fasuyi e Aletor (2005), o concentrado protéico de folha de mandioca possui quantidade razoável de aminoácidos essenciais e, devido ao seu alto conteúdo em lisina, poderia suplementar alimentos que possuem deficiência nesse aminoácido, como os cereais.

Entre as diversas alternativas utilizadas para extração de proteínas podem-se citar os métodos de extração por precipitação isoelétrica (ação da variação do $\mathrm{pH}$ ), termocoagulação (ação da temperatura), por autocoagulação (fermentação), floculação, ultrafiltração ou extração com solventes orgânicos, como etanol, butanol, acetona e éter (CHAVES, 1987; CEREDA; VILPOUX, 2003; FERRI, 2006; DEWAN et al., 2007; MODESTI et al., 2007; TEO et al., 2010). 
Considerando este cenário, o presente trabalho teve como objetivo avaliar quatro métodos para obtenção de concentrados protéicos de folhas e parte aérea da mandioca (Manihot esculenta Crantz), bem como a composição mineral e as propriedades funcionais dos concentrados obtidos.

\section{Material e Métodos}

\section{Coleta e Caracterização do Material}

As partes aéreas da mandioca (Manihot esculenta Crantz), da variedade Fécula Branca cultivada na região oeste do Paraná, foram coletadas aleatoriamente em plantas com idade de 18 meses e acondicionadas em sacos plásticos para transporte até o local de preparo. As partes aéreas foram separadas em folhas, hastes e caules, lavadas com água corrente e água destilada. E, posteriormente, dispostas em estufa de circulação de ar a $60^{\circ} \mathrm{C}$ por 12 horas. Após a secagem o material foi triturado.

A parte aérea de mandioca foi constituída de partes iguais das três frações, inicialmente separadas (33,3\% de folhas, $33,3 \%$ de hastes e 33,3\% de caules). As folhas de mandioca desidratadas apresentaram teor de umidade de $9 \%$ e de proteína bruta média de 25,69\% em massa seca, enquanto a parte aérea desidratada apresentou 9,29\% de umidade e proteína bruta média em base seca de $20,75 \%$.

\section{Obtenção dos Concentrados Protéicos}

A obtenção da suspensão de folhas de mandioca resultou da mistura de $100 \mathrm{~g}$ de folhas, secas e trituradas, com $1.000 \mathrm{~mL}$ de água destilada em um liquidificador, na proporção de 1:10 (p/v), durante 5 minutos. O procedimento para obtenção da suspensão de parte aérea de mandioca foi similar ao anterior, utilizando a parte aérea da mandioca desidratada, alterando a proporção para 1:13 (p/v), devido à dificuldade de homogeneizar o material na presença de caules.
Para a obtenção dos concentrados protéicos, tanto das folhas (CPFM), quanto da parte aérea de mandioca (CPPAM), foram avaliados quatro métodos de extração de proteínas:

Método 1-- Extração por Precipitação Isoelétrica (CEREDA; VILPOUX, 2003).

Volumes de $1.000 \mathrm{~mL}$ do suco de folhas e da parte aérea tiveram o $\mathrm{pH}$ ajustado para o valor 8,0, com solução de $\mathrm{NaOH}$ 0,1 N. Em seguida filtraram-se os sucos em peneira de malha fina e, posteriormente, em tecido de algodão, separando-se o suco verde do resíduo fibroso. Depois de filtrado, o extrato passou por nova correção de $\mathrm{pH}$ para 4,0, com solução de $\mathrm{HCl} 0,1 \mathrm{~N}$, permanecendo em repouso durante 24 horas, sob refrigeração a $4^{\circ} \mathrm{C}$. Na sequência a amostra foi centrifugada por 10 minutos a 3.200 rpm, obtendo-se uma fração sobrenadante e um precipitado. O precipitado passou pelo processo de secagem em estufa com circulação e renovação de ar à temperatura de $60^{\circ} \mathrm{C}$.

Método 2 - Extração por Fermentação Natural do Suco por 5 dias (CHAVES, 1987).

Os sucos das folhas e parte aérea de mandioca tiverem o $\mathrm{pH}$ ajustado para 8,0 com $\mathrm{NaOH} 0,1$ N. Em seguida filtrou-se o extrato em peneira de malha fina e, posteriormente, em tecido de algodão, separando-se o suco verde do resíduo fibroso. O extrato clarificado foi submetido à fermentação natural em frascos de vidro, durante 5 dias à temperatura ambiente. Com a fermentação, o pH baixou naturalmente, promovendo a separação das frações. Logo em seguida, a solução foi centrifugada por 10 minutos a $3.200 \mathrm{rpm}$, obtendo-se uma fração sobrenadante e um precipitado. O precipitado passou pelo processo de secagem em estufa com circulação e renovação de ar à temperatura de $60^{\circ} \mathrm{C}$, para obtenção do concentrado protéico.

Método 3 - Extração por Fermentação Natural do Suco por 48 horas em temperatura ambiente (FERRI, 2006 adaptado de CHAVES, 1987). 
A extração por este método foi realizada nas mesmas condições do método anterior, diferindo apenas no tempo de fermentação, no qual se empregou 48 horas em temperatura ambiente.

Método 4 - Extração por Fermentação Natural do Suco por 5 dias com alteração do $\mathrm{pH}$ no final (FERRI, 2006 adaptado de CHAVES, 1987).

A extração por este método foi realizada nas mesmas condições do método 2, diferindo após 5 dias de fermentação, no qual o $\mathrm{pH}$ do fermentado foi ajustado para 4,0 com $\mathrm{HCl} 0,1 \mathrm{~N}$. Logo em seguida, a solução foi centrifugada por 10 minutos a $3.200 \mathrm{rpm}$, obtendo-se uma fração sobrenadante e um precipitado. O precipitado foi seco a $60^{\circ} \mathrm{C}$ em estufa com circulação e renovação de ar para obtenção do concentrado protéico.

\section{Cálculo do Balanço de Massa dos Processos de Extração}

Para determinar o rendimento de extração de proteína e o rendimento de concentrado protéico da folha e parte aérea de mandioca, foi realizado o balanço de massa, considerando o processo em regime permanente, em que, a massa que entra no processo deve ser igual à massa que sai do processo. Para cada etapa de separação dos métodos de extração de proteína, foram quantificadas as massas. Foi realizado o balanço em termos de massa seca e massa de proteína bruta, calculada em base seca.

O rendimento de extração de proteína foi determinado pelo cálculo da quantidade de concentrado em relação à de folhas e parte aérea desidratadas e moídas, (Equação 1).

Rendimento de Extração (\%) $=\frac{\text { PBCP }}{\text { PBIE }} \times 100$

Em que:

PBCP $=$ massa de Proteína Bruta do Concentrado Protéico $(\mathrm{g})$;

PBIE = massa de Proteína Bruta presente no Início da Extração (g).
O rendimento de concentrado protéico foi calculado pela equação (2):

Rendimento de Concentrado Protéico $(\%)=\frac{\text { MCP }}{\text { MIE }} \times 100$

Onde:

$\mathrm{MCP}=$ massa do Concentrado Protéico $(\mathrm{g})$ em base seca;

MIE = massa de Folha de Mandioca ou Parte Aérea presente no Início da Extração em base seca (g).

\section{Análises}

Para a determinação da umidade foi utilizado o método padrão da estufa, com secagem em estufa simples a $105^{\circ} \mathrm{C}$, até peso constante. O conteúdo de proteína bruta foi determinado com base no conteúdo de nitrogênio total, dosado pelo método Kjeldahl, utilizando o fator de conversão para proteína bruta de 6,25 . Os procedimentos seguiram metodologias descritas pelo Instituto Adolfo Lutz (2008).

A análise da composição mineral, com determinação da concentração de Ferro (Fe), Manganês (Mn), e Zinco ( $\mathrm{Zn})$, foi realizada pela digestão por via úmida seguida de leitura em espectrofotômetro de absorção atômica (marca Varian), segundo método da AOAC (1995).

Para a determinação das propriedades funcionais utilizou-se a análise de absorção de água e óleo, segundo o método de Okezie e Bello (1988). Uma suspensão com $1 \mathrm{~g}$ de amostra e $50 \mathrm{~mL}$ de água ou de óleo foi preparada em tubos de centrífuga, agitada em agitador de tubos durante 1 minuto, e centrifugada a $1500 \mathrm{rpm}$ por 20 minutos, desprezando-se o sobrenadante. A diferença entre o peso da amostra antes e após a absorção de água ou de óleo, foi tomada como a quantidade de água ou de óleo absorvida. A capacidade de absorção foi expressa como a quantidade de água ou de óleo absorvida por $100 \mathrm{~g}$ de amostra. 
Para a comparação dos métodos de extração, em termos de rendimento de concentrado e rendimento de extração, foi utilizado o delineamento experimental fatorial $2 \times 4$, sendo os fatores tipo de material (folhas e parte aérea) e Método de Extração de Proteína (4 métodos), com três repetições, perfazendo o total de 24 parcelas experimentais. Os resultados obtidos foram submetidos à análise de variância (ANOVA) e teste de comparação de médias (Teste de Tukey) ao nível de 5\% de significância, através do programa Sisvar.

\section{Resultados e Discussão}

Os valores de rendimento de concentrado protéico, rendimento de extração de proteína e teor de proteína bruta dos concentrados de folhas e parte aérea de mandioca encontram-se na Tabela 1.

Tabela 1. Valores de rendimento de concentrado protéico, rendimento da extração de proteína e proteína bruta nos concentrados obtidos pelos quatro Métodos de extração.

\begin{tabular}{ccccccc}
\hline \multirow{2}{*}{$\begin{array}{c}\text { Método } \\
\text { de } \\
\text { Extração }\end{array}$} & \begin{tabular}{c} 
Rendimento \\
\cline { 2 - 6 }
\end{tabular} & $\begin{array}{c}\text { Rendimento } \\
\text { Concentrado } \\
\text { dextração de } \\
\text { Proteína }\end{array}$ & $\begin{array}{c}\text { Teor de } \\
\text { Proteína }\end{array}$ & $\begin{array}{c}\text { Rendimento } \\
\text { Concentrado }\end{array}$ & $\begin{array}{c}\text { Rendimento } \\
\text { Extração de } \\
\text { Proteína }\end{array}$ & $\begin{array}{c}\text { Teor de } \\
\text { Proteína }\end{array}$ \\
\hline 1 & $18,31^{\mathrm{bB}}$ & $32,60^{\mathrm{bC}}$ & $45,90^{\mathrm{bB}}$ & $3,66^{\mathrm{aA}}$ & $8,63^{\mathrm{aA}}$ & $48,96^{\mathrm{bB}}$ \\
2 & $14,11^{\mathrm{bA}}$ & $25,95^{\mathrm{bB}}$ & $45,91^{\mathrm{bB}}$ & $6,10^{\mathrm{aB}}$ & $7,05^{\mathrm{aA}}$ & $24,08^{\mathrm{aA}}$ \\
3 & $14,40^{\mathrm{bA}}$ & $28,90^{\mathrm{bB}}$ & $48,20^{\mathrm{bB}}$ & $6,30^{\mathrm{aB}}$ & $8,30^{\mathrm{aA}}$ & $27,31^{\mathrm{aA}}$ \\
4 & $13,45^{\mathrm{bA}}$ & $18,06^{\mathrm{bA}}$ & $35,09^{\mathrm{bA}}$ & $6,55^{\mathrm{aB}}$ & $8,55^{\mathrm{aA}}$ & $27,26^{\mathrm{aA}}$ \\
\hline
\end{tabular}

Letras minúsculas iguais na linha não diferem entre si de acordo com o teste de Tukey ao nível de 5\% significância para o tipo de material; Letras maiúsculas iguais na coluna não diferem entre si (teste de Tukey ao nível de 5\% significância) para os métodos utilizados; Valores calculados em base seca.

Fonte: Elaboração dos autores.

Diferenças significativas entre o rendimento de concentrado protéico, rendimento de extração de proteína e teor de proteína na obtenção dos CPFM e CPPAM foram observados na Tabela 1. Para as folhas desidratadas de mandioca o rendimento de extração de proteína e o rendimento de concentrado foram de duas a quatro vezes maiores que os resultados obtidos para a parte aérea desidratada de mandioca. O que é bastante coerente com a composição das matérias-primas, considerando que as folhas têm maior teor de proteína $(25,69 \%)$ que a parte aérea $(20,75 \%)$.

O Método 1 proporcionou o maior rendimento de concentrado protéico nas folhas, e os menores rendimentos para a parte aérea de mandioca. Os menores rendimentos de CPPAM devem-se ao fato desta fração ser uma proporção de $33 \%$ de folhas, $33 \%$ de haste e $33 \%$ de pecíolo. Dessa forma, como nesse material a massa inicial de folhas desidratadas é bem menor, é esperado que ocorra uma redução significativa na quantidade do produto obtido, uma vez que a maior concentração de proteína encontrase na folha.

Em relação ao rendimento de extração de proteína das folhas, o Método 1 foi o que apresentou maior porcentagem de extração (Tabela 1). Não houve diferença significativa entre os Métodos 2 e 3 , indicando que o aumento do tempo de fermentação não influenciou no rendimento de extração. Ainda em relação às folhas de mandioca, observa-se que o menor rendimento de extração foi verificado para o Método 4, o que sugere que é inviável o gasto 
com a redução do $\mathrm{pH}$ nas indústrias para um bom rendimento de extração de proteínas. Não foram verificadas diferenças significativas entre os métodos de extração de proteína na parte aérea de mandioca.

Os teores de proteína encontrados nos CPFM pelos Métodos 1, 2 e 3 não diferiram estatisticamente. O maior teor de proteína encontrado para a parte aérea foi no Método 1, que diferiu estatisticamente dos demais métodos de extração (Tabela 1).

Ferri (2006) estudando a extração de proteínas de folhas de mandioca pelo Método 1 observou rendimento de extração de $48,70 \%$, rendimento de concentrado de $35,61 \%$ e teor de proteína no concentrado de $50,00 \%$, e pelo Método 3 observou rendimento de extração de $36,20 \%$, rendimento de concentrado de $25,86 \%$ e teor de proteína de 51,24 $\%$. No presente trabalho, obtiveram-se valores menores quando comparados com aos valores obtidos por Ferri (2006), provavelmente, devido aos diferentes cultivares e à idade da planta utilizada. Enquanto Ferri (2006) utilizou folhas de plantas na idade de 12 meses, considerada colheita precoce, na presente pesquisa, as folhas e parte aérea foram obtidas de plantas com idade de 18 meses, o que pode ser considerada uma colheita tardia.

Chaves (1987) que descreveu o Método 2, obteve concentrados protéicos com teores de $71,50 \%$ e rendimento de concentrado de $44,00 \%$, utilizando folhas frescas. O uso da mesma metodologia, mas com fermentação de folhas desidratadas, proporcionou teor de proteína de 45,91\% e rendimento de concentrado de $14,11 \%$. Apesar dos menores rendimentos encontrados para o material desidratado, esta opção foi utilizada a fim de reduzir a concentração de compostos tóxicos presentes no material fresco. Corrêa et al. (2002) afirmam que as folhas desidratadas possuem maior durabilidade, não apresentando o problema de degradação, além disso, a enzima linamarase fica inativada, eliminando o cianeto presente no material fresco.

O Método 1 citado por Cereda e Vilpoux (2003) se apresentou como o mais indicado por proporcionar os melhores resultados, em menor tempo de extração e ainda por se constituir de procedimentos simples. Este resultado corrobora com a pesquisa realizada por Ferri (2006).

$\mathrm{Na}$ Tabela 2 são apresentados os valores da composição mineral para as frações iniciais da parte aérea, calculados em base seca.

Os valores médios da concentração de $\mathrm{Fe}, \mathrm{Mn}$ e $\mathrm{Zn}$ para os concentrados protéicos, obtidos das folhas e parte aérea, para cada método de extração, estão apresentados na Tabela 3.

Tabela 2. Valores da composição mineral para as frações da parte aérea.

\begin{tabular}{cccc}
\hline \multirow{2}{*}{ MATERIAL } & Fe & Mn & Zn \\
& & - & \\
\hline Folhas & 203,00 & 26,00 & 27,50 \\
Haste & 35,00 & 37,00 & 5,00 \\
Pecíolo & 29,50 & 9,50 & 15,00 \\
Parte Aérea & 139,00 & 29,50 & 31,50 \\
\hline
\end{tabular}

Valores calculados em base seca.

Fonte: Elaboração dos autores. 
Tabela 3. Valores médios das concentrações de Fe, Mn e Zn encontrados nos concentrados de folhas e parte aérea da mandioca.

\begin{tabular}{|c|c|c|c|c|c|c|}
\hline \multirow{3}{*}{$\begin{array}{l}\text { Método de } \\
\text { Extração }\end{array}$} & \multicolumn{3}{|c|}{ FOLHAS } & \multicolumn{3}{|c|}{ PARTE AÉREA } \\
\hline & $\mathrm{Fe}$ & $\mathrm{Mn}$ & $\mathrm{Zn}$ & $\mathrm{Fe}$ & $\mathrm{Mn}$ & $\mathrm{Zn}$ \\
\hline & $----\cdot-$ & \multicolumn{2}{|c|}{ (mg/kg) ------------------- } & \multicolumn{3}{|c|}{--------------(mg/kg) ------------ } \\
\hline 1 & $119,16^{\mathrm{aB}}$ & $8,50^{\mathrm{aA}}$ & $10,33^{\mathrm{aA}}$ & $221,00^{\mathrm{bD}}$ & $17,50^{\mathrm{bA}}$ & $16,33^{\mathrm{bA}}$ \\
\hline 2 & $118,16^{\mathrm{aB}}$ & $20,33^{\mathrm{aC}}$ & $25,50^{\mathrm{aB}}$ & $131,16^{\mathrm{aB}}$ & $28,66^{\mathrm{bC}}$ & $24,33^{\mathrm{aB}}$ \\
\hline 3 & $94,00^{\mathrm{aA}}$ & $21,50^{\mathrm{aC}}$ & $26,00^{\mathrm{aB}}$ & $163,00^{\mathrm{bC}}$ & $37,00^{\mathrm{bD}}$ & $29,00^{\mathrm{bC}}$ \\
\hline 4 & $159,33^{\mathrm{bC}}$ & $17,83^{\mathrm{aB}}$ & $22,66^{\mathrm{aB}}$ & $85,16^{\mathrm{aA}}$ & $22,50^{\mathrm{bB}}$ & $23,33^{\mathrm{aB}}$ \\
\hline
\end{tabular}

Letras minúsculas iguais na linha não diferem entre si de acordo com o teste de Tukey ao nível de 5\% significância para o tipo de material; Letras maiúsculas iguais na coluna não diferem entre si (teste de Tukey ao nível de 5\% significância) para os métodos utilizados; Valores calculados em base seca.

Fonte: Elaboração dos autores.

As folhas de mandioca são geralmente ricas em ferro, como se pode observar na Tabela 2, a concentração de Fe inicial em peso seco foi de 203 $\mathrm{mg} / \mathrm{kg}$ na folha e de $139 \mathrm{mg} / \mathrm{kg}$ na parte aérea. Após a extração do CPFM a maior concentração de Fe foi de $159,33 \mathrm{mg} / \mathrm{kg}$ pelo Método 4, e para os CPPAM a concentração de Fe aumentou para $221 \mathrm{mg} / \mathrm{kg}$ com o Método 1 (Tabela 3). Melo et al. (2007) e Wobeto et al. (2007) relatam que teores de Fe, em peso seco, nas folhas de mandioca variam na faixa de 105,77 a $225,60 \mathrm{mg} / \mathrm{kg}$, para diferentes cultivares, estando os valores encontrados neste trabalho dentro do intervalo citado pelos autores.

O Método 3 proporcionou as maiores concentrações de $\mathrm{Mn}$ e $\mathrm{Zn}$ nos concentrados protéicos obtidos (Tabela 3) comparados com as concentrações iniciais (Tabela 2). Em relação ao CPFM as concentrações obtidas foram de 21,5 mg/ $\mathrm{kg}$ para o $\mathrm{Mn}$ e $26 \mathrm{mg} / \mathrm{kg}$ para o $\mathrm{Zn}$, enquanto para o CPPAM foram $37 \mathrm{mg} / \mathrm{kg}$ de $\mathrm{Mn}$ e $29 \mathrm{mg} / \mathrm{kg}$ para o $\mathrm{Zn}$. De forma geral, observa-se para todos os métodos de extração, que a parte aérea da mandioca apresentou as maiores concentrações de $\mathrm{Mn}$ e $\mathrm{Zn}$ no produto final. Melo et al. (2007) e Wobeto at al. (2007) relatam que teores de $\mathrm{Mn}$ em base seca nas folhas de mandioca variam de 50,30 a 333,69 $\mathrm{mg} / \mathrm{kg}$. Apesar dos valores encontrados serem menores que os valores citados acima, sabe-se que a concentração dos minerais varia de acordo com a idade e cultivar da planta (PEQUENO et al., 2007), e possivelmente, o cultivar utilizado neste estudo, apresente naturalmente menores teores de $\mathrm{Mn}$, ou a idade de 18 meses da planta tenha reduzido a sua concentração. Todas as concentrações de $\mathrm{Zn}$ em base seca encontradas nesse trabalho estão na faixa de 4,05 a 91,89 mg/kg, obtidas por Melo et al. (2007) e Wobeto et al. (2007).

Os concentrados protéicos apresentam teores de minerais dentro da faixa de variação citada na literatura (MELO et al., 2007; WOBETO et al., 2007), característica já esperada devido às folhas de mandioca também serem ricas em minerais (DIAS; LEONEL, 2006). Entretanto, o fato da extração das proteínas concentrarem esses minerais no produto final é uma observação original, assim como, a parte aérea da mandioca, pouco citada como fonte de minerais, revelar-se uma boa alternativa para alimentos igualmente ricos em minerais.

Na Tabela 4 encontram-se os resultados obtidos para a capacidade de absorção de água e óleo dos concentrados protéicos obtidos pelos quatro métodos de extração de proteína utilizando as folhas e parte aérea da mandioca. 
Tabela 4. Valores médios de absorção de água e óleo dos concentrados protéicos obtidos pelos métodos de extração para folha e parte aérea.

\begin{tabular}{ccccc}
\hline Método de & \multicolumn{2}{c}{ Absorção no CPFM } & \multicolumn{2}{c}{ Absorção no CPPAM } \\
Extração & Água (\%) & Óleo (\%) & Água (\%) & Óleo (\%) \\
\hline 1 & $190,33^{\mathrm{aA}}$ & $436,33^{\mathrm{aB}}$ & $345,33^{\mathrm{bC}}$ & $535,00^{\mathrm{bC}}$ \\
2 & $161,67^{\mathrm{aA}}$ & $318,33^{\mathrm{aA}}$ & $254,33^{\mathrm{bA}}$ & $385,33^{\mathrm{bA}}$ \\
3 & $434,00^{\mathrm{bC}}$ & $558,67^{\mathrm{bC}}$ & $305,00^{\mathrm{aB}}$ & $389,33^{\mathrm{aA}}$ \\
4 & $338,33^{\mathrm{bB}}$ & $535,33^{\mathrm{bC}}$ & $263,33^{\mathrm{aA}}$ & $443,00^{\mathrm{aB}}$ \\
\hline
\end{tabular}

Letras minúsculas iguais na linha não diferem entre si de acordo com o teste de Tukey ao nível de $5 \%$ significância para o tipo de material; Letras maiúsculas iguais na coluna não diferem entre si (teste de Tukey ao nível de $5 \%$ significância) para os métodos utilizados; Valores calculados em base seca.

Fonte: Elaboração dos autores.

Diferenças significativas nas propriedades funcionais de absorção de água e óleo dos concentrados de folhas e da parte aérea, obtidos pelos métodos de extração estudados, são observadas na Tabela 4. Verifica-se que para os CPFM o Método 3 proporcionou a maior capacidade de absorção de água e óleo nos extratos obtidos, enquanto para os CPPAM o Método 1 apresentou-se melhor (Tabela 4). No presente trabalho não foram realizados testes em produtos, no entanto, Aletor (2010) encontrou valor médio da capacidade de absorção de água de $158 \%$ para os extratos protéicos de folhas de mandioca, tendo afirmado que este valor é útil para a elaboração de produtos viscosos.

Desta forma, os resultados obtidos para absorção de água e óleo indicam potencial para aplicação industrial dos concentrados protéicos obtidos de folhas e parte aérea de mandioca na preparação de produtos que necessitam boas características de absorção, como salsichas, massas de bolos, maionese e outros molhos para saladas.

\section{Conclusões}

O método de extração por Precipitação Isoelétrica (Método 1) proporcionou os melhores resultados de rendimento de concentrado protéico e extração de proteína nas folhas, constituindo-se um método simples e rápido;
Os teores de minerais dos concentrados protéicos foram maiores do que os teores das folhas e parte aérea da mandioca, com destaque ao Método 3 para o manganês e o zinco;

As capacidades de absorção de água e de óleo dos concentrados protéicos de folha de mandioca foram maiores utilizando o Método 3, enquanto para o concentrado protéico da parte aérea da mandioca o Método 1 apresentou-se melhor.

\section{Referências}

ALETOR, O. Comparative, nutritive and physicochemical evaluation of cassava (Manihotesculenta) leaf protein concentrate and fish meal. Journal of Food Agriculture and Environment, Finlândia, v. 8, n. 2, p. 3943, 2010.

ASSOCIATION OF OFFICIAL AGRICULTURAL CHEMISTS - AOAC. Official methods of analysis of the AOAC. 15. ed. Washington, DC: AOAC, 1995.

BOHNENBERGER, L.; GOMES, S. D; COELHO, S. R. M.; BOSCOLO, W. R. Concentrado protéico de folhas de mandioca na alimentação de tilápias-do-nilo na fase de reversão sexual. Revista Brasileira de Zootecnia, Viçosa, MG, v. 39, n. 6, p. 1169-1174, 2010.

CEREDA, M. P.; VILPOUX, O. Potencialidades das proteínas de folhas de mandioca. In: CEREDA, M. P. Tecnologias, usos e potencialidades de tuberosas amiláceas latino americanas. São Paulo: Fundação Cargill, 2003. v. 3, p. 683-693.

CHAVES, J. G. Extrato protéico das folhas de mandioca. Informe Agropecuário, Belo Horizonte, v. 13, n. 145, p. 47-52, jan. 1987. 
CORRÊA, A. D.; SANTOS, C. D.; NATIVIDADE, M. A. E.; ABREU, C. M. P.; XISTOS, A. L. R. P.; CARVALHO, V. D. Farinha de Folhas de mandioca i - efeito da secagem das folhas sobre a atividade da Linamarase. Ciência e Agrotecnologia, Lavras, v. 26, n. 2, p. 368-374, 2002.

DEWAN, P.; KAUR, I.; CHATTOPADHYA, D.; FARIDI, M. M. A.; AGARWAL, K. N. A pilot study on the effects of curd (dahi) \& leaf protein concentrate in children with protein energy malnutrition (PEM). Indian Journal of Medical Research, New Delhi, v. 126, n. 4, p. 199-203, 2007.

DIAS, L. T.; LEONEL, M. Caracterização físico-química de farinhas de mandioca de diferentes localidades do Brasil. Ciência e Agrotecnologia, Lavras, v. 30, n. 4, p. 692-700, jul./ago. 2006.

FASUYI, A. O.; ALETOR, V. A. Varietalcomposition and functional properties of cassava (Manihot esculenta Crantz) leaf meal and leaf protein concentrates. Pakistan Journal of Nutrition, Faisalabad, v. 4, n. 1, p. 43-49, 2005.

FERRI, P. Extração de proteinas de folhas de mandioca (Manihot esculenta Crantz), para obtenção do concentrado protéico. 2006. Dissertação (Mestrado em Engenharia Agrícola) - Universidade Estadual do Oeste do Paraná, Cascavel.

INSTITUTO BRASILEIRO DE GEOGRAFIA E ESTATÍSTICA - IBGE. Estatísticas. 2012. Disponível em:<http://www.ibge.gov.br/home/estatistica/ indicadores/agropecuaria/lspa/lspa_201202_5.shtm.>. Acesso em: 08 mar. 2012.

INSTITUTO ADOLFO LUTZ - IAL. Normas analíticas do Instituto Adolfo Lutz. Métodos químicos e físicos para análise de alimentos. 3. ed. São Paulo: Instituto Adolfo Luiz, 2008.

LEONEL, M. Caracterização da fibra e uso do farelo de mandioca como base para produtos dietéticos. Manejo, uso e tratamento de subprodutos da industrialização da mandioca. São Paulo: Fundação Cargill, 2001. 320 p. (Série Culturas de tuberosas amiláceas Latino Americanas, v. 4).
MELO, D. S.; CORRÊA, A. D. ; MARCOS, F. C. A.; SOUZA, R. V.; ABREU, C. M. P.; SANTOS, C. D. Efeitos da farinha de folhas de mandioca sobre a peroxidação lipídica, o perfil lipídico sangüíneo e o peso do fígado de ratos. Ciência Agrotecnologia, Lavras, v. 31, n. 2, p. 420-428, 2007.

MODESTI, C. F.; CORRÊA, A. D.; OLIVEIRA, E. D.; ABREU, C. P. M.; SANTOS, C. D. Caracterização de concentrado protéico de folhas de mandioca obtido por precipitação com calor e ácido.Ciência e Tecnologia de Alimentos, Campinas, v. 27, n. 3, p. 464-469, 2007.

OKEZIE, B.; BELLO, A. B. Physico-chemical and functional properties of winged beans flour and isolated compared with soy isolated. Journal of Food Science, Chicago, v. 53, n. 2, p. 450, 1988.

PEQUENO, M.; VIDIGAL FILHO, P. S.; TORMENA, C.; KVITSCHAL, M. V.; MANZOTTI, M. Efeito do sistema de preparo do solo sobre características agronômicas da mandioca (Manihot esculenta Crantz). Revista Brasileira de Engenharia Agricola e Ambiental, Campina Grande, v. 11, n. 3, p. 476-481, 2007.

SAGRILO, E.; VIDIGAL FILHO, P. S.; PEQUENO, M. G.; GONÇALVES-VIDIGAL, M. C.; KVITSCHAL, M. $\mathrm{V}$. Dry matter production and distribution in three cassava (Manihot esculenta Crantz) cultivars during the second vegetative plant cycle. Brazilian Archives of Biology and Technology, Curitiba, v. 51, n. 6, p. 1079-1087, 2008.

SILVA, A. F.; SANTANA, L. M. de; FRANÇA, C. R. R. S.; MAGALHÃeS, C. A. de S.; ARAÚJO, C. R. de; AZEVEDO, S. G. de. Produção de diferentes variedades de mandioca em sistema agroecológico. Revista Brasileira de Engenharia Agrícola e Ambiental, Campina Grande, v. 13, n. 1, p. 33-38, 2009.

TEO, C. R. P. A.; PRUDENCIO, S. H.; COELHO, S. R. M.; TEO, M. S. Obtenção e caracterização físicoquímica de concentrado protéico de folhas de mandioca. Revista Brasileira de Engenharia Agrícola e Ambiental, Campina Grande, v. 14, n. 9, p. 993-999, 2010.

WOBETO, C.; CORRÊA, A. D.; ABREU, C. M. P.; PEREIRA, H. V. Antinutrients in the cassava (Manihot esculenta Crantz) leaf powder at three ages of the plant. Ciência e Tecnologia de Alimentos, Campinas, v. 27, n. 1, p. 108-112, 2007. 
